\title{
Detección de anticuerpos I gA y PCR como primeras opciones en el diagnóstico de infección perinatal por el VIH-1
}

\author{
Ma del C armen Basualdo, Q FB, ${ }^{(1)}$ Kathya Moran, Q FB, ${ }^{(1)}$ Patricia A lcántara, M en $C$, (1) \\ Elizabeth $\mathrm{G}$ onzález, Q BP, ${ }^{(1)}$ Esteban Puentes, $M$ en $C{ }^{(2)}$ Carmen Soler, $M$ en $C$. ${ }^{(1)}$
}

\section{Basualdo MC, Moran K, Alcántara P, González E, Puentes E, Soler C. Detección de anticuerpos IgA y PCR como primeras opciones en el diagnóstico de infección perinatal por el VIH-1. Salud Publica Mex 2004;46:49-55.} El texto completo en inglés de este artículo está disponible en: http://www.insp.mx/salud/index.html

\section{Resumen}

Objetivo. Evaluar la sensibilidad y especificidad de la reacción en cadena de la polimerasa y de las pruebas de ELISA e inmunoblot para anticuerpos IgA específicos, como únicos métodos en el diagnóstico de infección perinatal del VIH-1. Material y métodos Estudio de evaluación comparativa, efectuado entre febrero y octubre de 2001 en la Unidad de Investigación en Retrovirus Humanos de la Universidad $\mathrm{N}$ acional Autónoma de México. Se incluyeron 90 muestras de niños infectados y 153 de no infectados. El cultivo viral fue la prueba de referencia. Se estandarizaron ensayos de ELISA e inmunoblot y la reacción en cadena de la polimerasa para una región conservada del gen gag. Se analizaron los resultados utilizando el paquete informático SPSS 10.0. Resultados La sensibilidad y especificidad de la prueba de ELISA fueron 61.1 y $90.8 \%$, respectivamente. En el inmunoblot encontramos 82.2 y $95.4 \%$, respectivamente, en tanto que la reacción en cadena de la polimerasa demostró tener sensibilidad de $98.3 \%$ y especificidad de $100 \%$ con sólo un falso negativo. Conclusiones. Los resultados indican que la realización simultánea de la reacción en cadena de la polimerasa y el inmunoblot para IgA logran sensibilidad y especificidad de $100 \%$ y $96 \%$, respectivamente, por lo cual se consideran útiles para el diagnóstico perinatal de VIH-1. El texto completo en inglés de este artículo está disponible en: http://www.insp.mx/salud/index.html

Palabras clave: IgA; reacción en cadena por polimerasa; diagnóstico perinatal; $\mathrm{VIH}$
Basualdo MC, Moran K,Alcántara P,

González E, Puentes E, Soler C.

IgA antibody detection and PCR

as first options in the diagnosis

of perinatal HIV-1 infection.

Salud Publica Mex 2004;46:49-55.

The English version of this paper

is available at: http://www.insp.mx/salud/index.htm

\section{A bstract}

Objective.To evaluate the sensitivity and specificity of the polymerase chain reaction (PCR), enzyme-linked immuno sorbent assay (ELISA) and IgA-specific immunoblot assays as ancillary methods to diagnose human immunodeficiency virus (HIV-1) perinatal infection. Material and Methods A comparative study was conducted between February and 0 ctober 2001 at the Human Retrovirus Research Unit of Mexico's N ational University. N inety infected and 153 noninfected children were included in the study.Viral cultures were the gold standard tests. Standardized PCR for a conserved region of the gag gene and HIV-specific IgA antibody using ELISA and immunoblot were used. Statistical analysis of results was performed with SPSS 10.0. Results. IgA ELISA sensitivity and specificity were $61.1 \%$ and $90.8 \%$, respectively. Immuno blot had a sensitivity of $82.2 \%$ and a specificity of $95.4 \%$. PCR had an overall sensitivity of $98.3 \%$ and a specificity of $100 \%$ with only one false negative result. If both assays were run, the sensitivity increased to $100 \%$ and the specificity to $96 \%$. Conclusions A very high sensitivity and specificity is reached when using to gether PC R and IgA immunoblot; these assays are useful for perinatal diagnosis of HIV-1. The English version of this paper is available at: http://www.insp.mx/salud/index.html

Key words: IgA; polymerase chain reaction; perinatal diagnosis; HIV

(1) Unidad de Investigación en Retrovirus Humanos. Universidad N acional Autónoma de México. Instituto de Diagnóstico y Referencia Epidemiológicos. Secretaría de Salud, México.

(2) Dirección General de Información y Evaluación del Desempeño. Secretaría de Salud, México.

Fecha de recibido: 10 de junio de 2003 • Fecha de aprobado: 17 de noviembre de 2003

Solicitud de sobretiros: Q FB Ma del Carmen Basualdo Sigales. Unidad de Servicios y Diagnóstico en VIH, Instituto de Investigaciones Biomédicas, Universidad N acional Autónoma de México. Coordinación del programa deVIH/SIDA, Secretaría de Salud del Distrito Federal, México. Benjamín Hill 24 colonia Condesa, D elegación Cuauhtémoc, 06140 México, DF, México. Correo electrónico: mcbasualdo@ yahoo.com 
L pandemia provocada por el VIH-1 ha afectado a

todos los grupos socioeconómicos y de edad en el mundo, incluyendo a los niños.

La transmisión madre-hijo puede ser intrauterina, aunque en la mayoría de los casos ésta se da durante el parto o posterior a él a través de la leche materna. ${ }^{1-3}$ El diagnóstico temprano de la infección en el recién nacido es muy importante para el manejo clínico, tanto con terapia antirretroviral como en la profilaxis de las infecciones oportunistas.

Sin embargo, como los anticuerpos maternos tipo IgG cruzan la placenta y se mantienen en el bebé en promedio durante 18 meses $^{4,5,6}$ los ensayos rutinarios de diagnóstico para la detección de IgG específica frente al VIH-1 no resultan útiles, por lo que se ha hecho necesario el uso de otros más complejos como el cultivo viral, la búsqueda de genoma viral integrado mediante la reacción en cadena de la polimerasa (PCR, por sus siglas en inglés), la detección de antígeno p24 en suero o plasma y de anticuerpos tipo IgA e IgM específicos frente al VIH-1.

Aun cuando el aislamiento viral ha sido considerado el ensayo de referencia en el diagnóstico perinatal del VIH-1 es un procedimiento caro y difícil de efectuar en la mayoría de los laboratorios de países en desarrollo, y ante la necesidad de lograr un diagnóstico certero y rápido en niños hijos de madres seropositivas, analizamos en este estudio la posibilidad de combinar la búsqueda de anticuerpos tipo IgA específicos para el VIH-1 por ELISA e inmunoblot con la detección de genoma viral integrado por la PCR como primera opción en el diagnóstico perinatal del VIH.

\section{Material y métodos}

El estudio de evaluación comparativa de métodos para el diagnóstico perinatal de VIH-1 se realizó en la Unidad de Investigación en Retrovirus Humanos de la Universidad Nacional Autónoma de México, entre febrero y octubre de 2001.

\section{Muestras biológicas}

Se incluyeron en el estudio 243 muestras de sangre completa de 222 niños de diferentes estados de la República Mexicana de entre 0 y 24 meses de edad. Las primeras muestras fueron 179, y 64 fueron muestras de seguimiento. Todas las muestras se colectaron de forma estéril con EDTA como anticoagulante, se mantuvieron a temperatura ambiente y se enviaron a nuestro laboratorio para ser procesadas en un tiempo no mayor a 24 hrs.

Las células mononucleares periféricas (PBMC) que se utilizaron para establecer el cultivo viral y para extraer el DNA para PCR se separaron mediante gradiente de ficoll. Los plasmas se mantuvieron congelados a $-70{ }^{\circ} \mathrm{C}$ hasta el momento de realizar los ensayos serológicos.

Se definieron como infectados aquellos niños de cuyas muestras se pudo aislar el virus, y como no-infectados aquellos en los que el cultivo fue negativo lo mismo que la detección de antígeno p24 en plasma, y en los que durante el seguimiento pudo demostrarse la serorreversión completa mediante la detección de anticuerpos tipo IgG por ELISA comercial (Genelavia Sanofi Pasteur, Marnes-la Coquette, France) e inmunoblot preparado en nuestro laboratorio.

\section{Cocultivo viral}

Se pusieron en cultivo $10 \times 10^{6} \mathrm{PBMC}$ no infectadas obtenidas de concentrados leucocitarios (proporcionados por el Banco de Sangre del Hospital de la Mujer de la Secretaría de Salud de México) con 4-6 X $10^{6}$ PBMC del paciente. Las PBMC no infectadas se activaron previo al cultivo por $48 \mathrm{hrs}$ con fitohemaglutinina $(2.5 \mu \mathrm{g} / \mathrm{ml})$ (Sigma). Se utilizó medio RPMI-1 640 (Gibco) suplementado con 15\% de suero fetal bovino (SFB) (Gibco) inactivado, 1\% de mezcla de antibióticos-antimicóticos (Gibco) y 10U/ml de IL-2 recombinante (Boehringer Mannheim). Los cocultivos se mantuvieron por 28 días alimentándose cada siete con $8 \times 10^{6}$ PBMC activadas no infectadas.

El seguimiento del cultivo se hizo cada siete días mediante la detección de antígeno p24 (Genetic systems HIV 1 Ag EIA Bio-Rad) en el sobrenadante de cultivo. Se consideró positivo el aislamiento cuando se demostró la presencia de p24 en dos determinaciones consecutivas y pudo confirmarse la especificidad del ensayo por neutralización del antígeno.

\section{Preparación del antígeno del VIH}

El virus prototipo IIIb/LAV se obtuvo del sobrenadante de cultivo de células Molt-4 infectadas y crecidas en medio RPMI 1640 suplementado con 10\% de SFB inactivado y $1 \%$ de mezcla de antibióticos-antimicóticos.

Los sobrenadantes de cultivo con el virus se centrifugaron $15 \mathrm{~min}$ a $3000 \mathrm{rpm}(600 \mathrm{~g})$ y se filtraron por una membrana de $0.45 \mathrm{~mm}$ para retirar la mayor parte de los desechos celulares. A continuación se colectó el virus por ultracentrifugación a $20000 \mathrm{rpm} / 2 \mathrm{hrs}$ y se realizó una purificación parcial usando una columna de Sepharosa 4B y posterior ultracentrifugación a $50000 \mathrm{rpm}$ por $1 \mathrm{hr} .^{7} \mathrm{La}$ pastilla viral se resuspendió en $500 \mathrm{ml}$ de PBS pH 7.4 y se cuantificaron proteínas por el método de Bradford; se hicieron alícuotas con 
$12 \mathrm{mg}$ de proteina/100 ml usando como diluyente PBStriton $\mathrm{X} 100$ a $0.5 \%$. El antígeno se conservó a $-70{ }^{\circ} \mathrm{C}$ hasta el momento de usarse.

\section{ELISA para IgA}

Las placas de ELISA (combiplate 8 Labsystems) se recubrieron con 100 ng de proteína/pozo diluida en PBS pH 7.4 dejando pegar toda la noche a temperatura ambiente (TA) en cámara húmeda.

La placa se lavó una vez con agua destilada utilizando un lavador automático y se bloqueó con PBSAlbúmina a $2 \%$ por 3 hrs a TA en cámara húmeda. Pasado este tiempo se realizaron dos lavados con agua destilada y se colocaron en cada pozo $100 \mu$ l de muestra diluida 1:200 en buffer de dilución (PBS-albúmina 1\% -Tween 20 0.05\%). Las muestras de plasma se centrifugaron previamente a $12000 \mathrm{rpm} 1 \mathrm{~min}$. Se incluyeron en cada ensayo tres controles negativos y dos positivos. Tanto muestras problema como controles se corrieron por duplicado.

La placa se incubó a TA toda la noche en cámara húmeda y al día siguiente se hicieron cinco lavados con agua destilada. La placa se sacudió fuertemente para eliminar todo residuo de agua y se agregaron $100 \mu \mathrm{l}$ cada pozo del anticuerpo anti-IgA conjugado con peroxidasa (Dako corporation) diluido 1:2 000 con buffer de dilución y se incubó $1 \mathrm{hr}$ a $37^{\circ} \mathrm{C}$ en cámara húmeda. Posteriormente se hicieron cinco lavados y se agregaron $100 \mu \mathrm{l}$ de una solución de $2 \mathrm{mg} / \mathrm{ml}$ de o-fenilen diamina en buffer de citrofosfatos (Acido cítrico $0.452 \mathrm{~g}$, fosfato dibásico de sodio $1.53 \mathrm{~g}$ en agua destilada $\mathrm{pH}$ final 5.5) con $15.8 \mu$ l de peróxido de hidrógeno de 30 vol. La placa se incubó a TA en la oscuridad por $20 \mathrm{~min}$.

La reacción se paró con $50 \mu l$ por pozo de $\mathrm{HCl} 1 \mathrm{~N}$ e inmediatamente se leyó la DO a $492 \mathrm{~nm}$.

La línea de corte se determinó para cada ensayo promediando los valores de DO de los controles negativos y sumando una desviación estándar de los propios controles negativos. Los controles positivos debieron tener valores de densidad óptica por encima de la línea de corte para considerar válido el ensayo.

\section{Inmunoblot para IgA}

Las tiras de nitrocelulosa que contenían antígeno IIIb/LAV de VIH-1 se incubaron a temperatura ambiente (TA) con agitación suave por 2 hrs con los plasmas diluidos 1:10 en buffer de dilución (PBS pH 7.4, albúmina a $1 \%$ y de Tween 20 a $0.2 \%$ ). Se utilizaron controles positivo y negativo para cada corrida.

Terminado este tiempo, las tiras se lavaron tres veces durante 5 min cada vez con buffer de lavado (PBS -Tween 20 a $0.2 \%$ ) y se incubaron $1 \mathrm{hr}$ a TA con una dilución 1:500 del anticuerpo anti-IgA conjugado con peroxidasa. Posteriormente se lavaron como se indicó anteriormente y se hizo un lavado final con PBS. La reacción se desarrolló con una solución de revelado (33 Diamino benzidina a $0.05 \%, \mathrm{H}_{2} \mathrm{O}_{2}$ a $0.05 \%$ y cloruro de cobalto a $0.03 \%$ en PBS) agitando suavemente hasta observar aparición clara de bandas en el control positivo. Se paró la reacción lavando con agua corriente. Se consideraron positivas las muestras que presentaran al menos una de las siguientes bandas virales: gp 160, gp 120, gp 41 o p24. ${ }^{8}$

\section{Reacción en cadena de la polimerasa}

Se extrajo el DNA total de $4 \times 10^{6} \mathrm{PBMC}$ de los pacientes empleando $5.25 \mathrm{ml}$ de buffer de reacción $(\mathrm{KCl} 500$ $\mathrm{mM}$, Tris- $\mathrm{HCl} 100 \mathrm{mM}$ pH 8.0), $5.25 \mathrm{ml}$ de Tween $20 \mathrm{a}$ $5 \%$ y $0.525 \mathrm{ml}$ de una solución inicial de $20 \mathrm{mg} / \mathrm{ml}$ de proteinasa K (Gibco-BRL) (concentración final 175 $\mathrm{mg} / \mathrm{ml}$ ). El volumen se llevó a $60 \mathrm{ml}$ con PBS pH 7.4. La lisis celular se realizó calentando a $55^{\circ} \mathrm{C} / 45 \mathrm{mi}$ nutos seguida de inactivación de la proteinasa $\mathrm{K}$ a $96^{\circ} \mathrm{C} / 10$ minutos. Para la amplificación se utilizaron los iniciadores SK462 que van del nucleótido 1358 al 1387 y SK431 que comprende del nucleótido 1473 al 1497 para definir una secuencia de 142 pares de bases de una región altamente conservada del gen gag. ${ }^{9}$ La mezcla de amplificación se preparó utilizando buffer 10X (Boeringer) $\mathrm{MgCl}_{2} 5 \mathrm{mM}, 1.25 \mathrm{mM}$ de cada uno de los dNTP, 1U/ $\mathrm{ml}$ de taq polimerasa (Boeringer), $25 \mathrm{pM}$ de cada uno de los iniciadores y $5 \mathrm{ml}$ del DNA problema en un volumen final de $50 \mathrm{ml}$. La amplificación se llevó a cabo en un termociclador Perkin Elmer 2400 bajo las siguientes condiciones: tres ciclos de 10 seg a $94{ }^{\circ} \mathrm{C}, 10 \mathrm{seg}$ a $55^{\circ} \mathrm{C}, 30$ seg a $72{ }^{\circ} \mathrm{C}$ seguidos de 32 ciclos de 10 seg a $94^{\circ} \mathrm{C}, 60^{\circ} \mathrm{C}$ y $72{ }^{\circ} \mathrm{C}$, respectivamente. La amplificación se completó con una extensión final de $72{ }^{\circ} \mathrm{C} / 5 \mathrm{~min}$.

Se prepararon controles positivos de 10 copias de DNA viral utilizando PBMC no infectadas y células Molt-4 infectadas con el virus IIIb/LAV, que se sometieron a amplificación junto con las muestras con el fin de establecer el límite de detección. Como control de la PCR se amplificó el gen de b-globina cuyo producto de amplificación es de 242 pares de bases.

Los productos de amplificación se visualizaron en geles de agarosa a $2.5 \%$ por tinción con bromuro de etidio.

\section{A nálisis estadístico}

La sensibilidad y la especificidad de las diferentes pruebas diagnósticas se evaluaron mediante los procedimientos tradicionales utilizando tablas de contingencia 
de $2 \times 2$. En todos los casos el ensayo de referencia fue el cultivo viral realizado bajo los procedimientos anteriormente descritos. Se evaluó la sensibilidad y especificidad del uso combinado del inmunoblot y de la PCR de dos formas alternativas. En primera instancia, se consideró positivo a toda aquella muestra que tuviera resultado positivo en cualquiera de las dos pruebas. La segunda estrategia consistió en evaluar las pruebas por el método llamado en paralelo. Bajo este esquema se considera positiva aquella muestra que resulta positiva en el inmunoblot; los negativos se someten a una segunda prueba. También se calculó el valor de concordancia mediante el estadístico kappa de Cohen. Además de los valores puntuales de las diferentes estimaciones se calcularon intervalos de confianza de $95 \%$ con el fin de establecer el nivel de incertidumbre para las estimaciones iniciales. ${ }^{10}$ Todos los procedimientos estadísticos se realizaron utilizando el paquete informático SPSS 10.0.

\section{Resultados}

Se analizaron 243 muestras de plasma de 222 niños de entre 0 y 24 meses de edad, hijos de madres seropositivas. De estas muestras 90 (37\%) correspondieron a niños confirmadamente infectados y 153 muestras (63\%) a niños definidos como no infectados en vista de que se pudo demostrar la serorreversión con ausencia total de datos clínicos que sugirieran infección, cultivo viral negativo y antígeno en plasma negativo. El 100\% de los niños no infectados incluidos en este estudio había serorrevertido a los 15 meses de edad. Las determinaciones de ELISA e inmunoblot para IgA se realizaron en la muestra completa (243 plasmas), en tanto que por PCR se ensayaron 210 muestras, 153 negativas y 57 positivas. El problema fundamental fue que el volumen de sangre recibido era muy poco y se dio prioridad al cultivo.

En el cuadro I se hace un resumen de los resultados de sensibilidad y especificidad de los diferentes ensayos por rangos de edad. Como puede observarse la sensibilidad de la prueba de ELISA en la muestra total es mucho menor que la del inmunoblot (61.1 vs $82.2 \%$ ). En ambos ensayos se observa una marcada disminución de la sensibilidad en los primeros tres meses de vida.

Si analizamos los datos de sensibilidad y especificidad de los tres ensayos excluyendo las muestras de niños de entre 0 y 3 meses de edad, dado que múltiples reportes indican la poca sensibilidad de los ensayos a esta edad, vemos que tanto la prueba de ELISA como el inmunoblot mejoran aunque no con significancia estadística $(p>0.10)$. En tanto que la PCR conserva los parámetros (cuadro II).

Con el fin de eliminar las variaciones normales entre ensayos en las pruebas de ELISA se sacaron promedios de los índices DO/LC en los verdaderos positivos (1.5714), falsos positivos (1.1487), verdaderos negativos $(0.660)$ y falsos negativos (0.735) observándose que la diferencia entre el valor promedio de verdaderos positivos y falsos positivos no es estadísticamente significativo $(p=0.07)$ quizá debido al tamaño de la muestra, sin embargo, nuestros resultados indican que sólo una muestra verdadera negativa tiene un índice DO/LC por encima de 1.35.

En el cuadro III se describe la frecuencia con que aparecen las diferentes bandas en el inmunoblot para IgA tomando en cuenta la muestra completa.

Como se puede observar, los anticuerpos a p24 son los más frecuentes, tanto en niños infectados (77.7\%) como en niños no infectados (3.2\%) sin embargo, aunque se observa una gran especificidad (98.7\%) en la presencia de anticuerpos frente a las glicoproteínas virales, si se elimina del criterio de positividad la presencia de p24, tendríamos 19 muestras diagnosticadas falsamente como negativas, con lo cual la sensibilidad del ensayo caería a $61.11 \%$

De las 16 muestras definidas como infectadas que fueron totalmente negativas en los ensayos de ELISA e inmunoblot de $\operatorname{IgA}$, ocho correspondieron a niños

\section{Cuadro I}

Datos de sensibilidad y especificidad de las pruebas de EliSA e inmunoblot para IgA y de la Reacción en Cadena de la polimerasa, en los diferentes grupos de edad. Ciudad de México, 2001

\begin{tabular}{|c|c|c|c|c|c|c|c|c|c|c|c|c|}
\hline & \multicolumn{2}{|c|}{0.3 meses } & \multicolumn{2}{|c|}{ 4-6 meses } & \multicolumn{2}{|c|}{ 7-12 meses } & \multicolumn{2}{|c|}{ 13-18 meses } & \multicolumn{2}{|c|}{ 19-24 meses } & \multicolumn{2}{|c|}{ Total } \\
\hline & Sensibilidad & Especificidad & Sensibilidad & Especificidad & Sensibilidad & Especificidad & Sensibilidad & Especificidad & Sensibilidad & Especificidad & Sensibilidad & Especificidad \\
\hline Elisa para & & & & & & & & & & & & \\
\hline $\lg A$ & $4 / 16 \quad 25 \%$ & $48 / 49 \quad 97.9 \%$ & $15 / 22 \quad 68.1 \%$ & $24 / 26 \quad 92.3 \%$ & $20 / 27 \quad 74.0 \%$ & $36 / 38 \quad 94.7 \%$ & $5 / 9 \quad 55.5 \%$ & $19 / 27 \quad 70.3 \%$ & $11 / 16 \quad 68.7 \%$ & $12 / 1392.3 \%$ & $55 / 90 \quad 61.1 \%$ & $139 / 15390.8 \%$ \\
\hline Inmunoblc & & & & & & & & & & & & \\
\hline para IgA & $8 / 1650 \%$ & $46 / 49 \quad 93.9 \%$ & $19 / 2286.3 \%$ & $24 / 26 \quad 92.3 \%$ & $25 / 27 \quad 92.8 \%$ & $36 / 3894.6 \%$ & $8 / 988.9 \%$ & $27 / 27 \quad 100 \%$ & $14 / 16 \quad 87.5 \%$ & $13 / 13 \quad 100 \%$ & $74 / 90 \quad 82.2 \%$ & $146 / 153 \quad 95.4 \%$ \\
\hline $\mathrm{CR}$ & $8 / 8 \quad 100 \%$ & $49 / 49 \quad 100 \%$ & $15 / 15 \quad 100 \%$ & $26 / 26 \quad 100 \%$ & $16 / 1794.11 \%$ & $37 / 37 \quad 100 \%$ & $6 / 6 \quad 100 \%$ & $27 / 27 \quad 100 \%$ & $12 / 12 \quad 100 \%$ & $13 / 13 \quad 100 \%$ & 98.27 & $152 / 152 \quad 100 \%$ \\
\hline
\end{tabular}




\section{Cuadro II Sensibilidad y Especificidad del ELISA, EL INMUNOBLot Y LA PCR EN MUESTRAS DE NIÑOS MAYORES DE 3 MESES}

\begin{tabular}{lccc} 
& Sensibilidad & Especificidad & Kappa de Cohen \\
178 muestras & $51 / 74$ & $91 / 104$ & \\
\hline ELISA & $68.91 \%$ & $87.50 \%$ & \\
\hline & $(56.96-78.89)$ & $(79.22-92.91)$ & 0.525 \\
& & & \\
178 muestras & $66 / 74$ & $100 / 104$ & \\
\hline Inmunoblot & $89.18 \%$ & $96.15 \%$ & \\
\hline & $(79.27-94.88)$ & $(91.18-99.25)$ & 0.872
\end{tabular}

\begin{tabular}{|c|c|c|c|}
\hline 153 muestras & $49 / 50$ & $103 / 103$ & \\
\hline \multicolumn{4}{|c|}{ Reacción en cadena de la } \\
\hline polimerasa & $98.0 \%$ & $100 \%$ & \\
\hline
\end{tabular}

Los valores entre paréntesis son los intervalos de confianza de $95 \%$

menores de tres meses de edad, por lo que los reportes anteriores indican que la sensibilidad en la detección de anticuerpos tipo IgA específicos está por debajo de $50 \% .{ }^{11,12}$ En 12 muestras pudo detectarse antígeno p24 en plasma y tres fueron negativas en el Inmunoblot para anticuerpos tipo IgG sugiriendo un importante deterioro en el sistema inmunológico que impide controlar la infección y quizá fabricar anticuerpos a niveles detectables.

El cuadro IV resume los datos obtenidos en la PCR, de lo cual se observa una sensibilidad de $98.27 \%$ y una especificidad de 100\% con límites de confianza de $95 \%$ de $(89.53-99,90)$ y $(96.94-100)$, respectivamente y Kappa de Cohen de 0.988. Sólo una muestra de un niño de 10 meses de edad resultó falsamente negativa y no se presentaron falsos resultados positivos.

\section{Discusión}

El objetivo de este estudio ha sido demostrar que la detección de anticuerpos tipo IgA específicos para VIH-1, en combinación con la amplificación por la PCR de una región altamente conservada del gen gag, son pruebas suficientemente sensibles y específicas para realizar el diagnóstico perinatal de infección por el VIH sin necesidad de utilizar el cultivo viral que resulta muy costoso y requiere instalaciones especializadas.

Los datos de sensibilidad y especificidad (61.1 y $90.8 \%$, respectivamente) obtenidos en la prueba de ELISA para anticuerpos tipo IgA estandarizada en nuestro laboratorio son similares a los obtenidos en estudios previos. ${ }^{8,12,13}$ Entre 0 y 3 meses de edad la sensibilidad es muy baja: $25 \%,{ }^{4-16}$ sin embargo, la especificidad es de $97.9 \%$. Estos datos concuerdan con estudios pre$\operatorname{vios}^{8,11,12,13}$ y apoyan que la mayoría de los niños se infectan durante el parto o en las primeras semanas de vida, ${ }^{3,14}$ y que la síntesis de novo de anticuerpos específicos frente al VIH-1 inicia aproximadamente en el segundo mes de vida y alcanza niveles detectables a los seis meses de edad en $75 \%$ de los casos. ${ }^{15}$

Analizando los índices DO/LC se puede observar una diferencia entre reacciones verdaderamente positivas y aquellas que no lo son. Cuando esta relación es igual o superior al valor arbitrario de 1.35 la posibilidad de falsos positivos es casi nula en todos

\section{Cuadro III \\ Frecuencia con la Que se presentan las diferentes bandas Virales en el inmunoblot de IGA, Ciudad de México, 2001}

\begin{tabular}{|c|c|c|c|c|c|c|c|c|c|}
\hline $\begin{array}{l}\text { Rangos de edad } \\
\text { en meses }\end{array}$ & $\begin{array}{l}\text { Número de muestras } \\
\text { de niños infectados }\end{array}$ & gp 160 & gp 120 & $p 66$ & p 55/51 & gp 41 & p 24 & p 17 & Sin bandas \\
\hline \multirow[t]{2}{*}{$0-3$} & 16 & 1 & 1 & 2 & 6 & 3 & 8 & 2 & 8 \\
\hline & & $(6.25)$ & $(6.25)$ & (12.5) & $(37.5)$ & (18.7) & $(50)$ & (12.5) & (50) \\
\hline \multirow[t]{2}{*}{$4-6$} & 22 & 11 & 3 & 10 & 15 & 5 & 18 & 2 & 3 \\
\hline & & (50) & $(13.6)$ & (45.4) & $(68.2)$ & (22.7) & $(81.8)$ & (9) & $(13.6)$ \\
\hline \multirow[t]{2}{*}{$7-12$} & 27 & 16 & 1 & 11 & 22 & 14 & 23 & 7 & 2 \\
\hline & & $(59.2)$ & (3.7) & $(40.7)$ & $(81.5)$ & (52) & $(85)$ & (26) & (7.4) \\
\hline \multirow[t]{2}{*}{ 13-18 } & 9 & 3 & 1 & 1 & 7 & 4 & 8 & 3 & 1 \\
\hline & & (33.3) & $(11.1)$ & (11.1) & $(77.7)$ & $(44.4)$ & $(88.8)$ & (33.3) & (11.1) \\
\hline \multirow[t]{2}{*}{$19-24$} & 16 & 5 & 1 & 5 & 13 & 9 & 13 & 2 & 2 \\
\hline & & $(31.2)$ & $(6.2)$ & (31.2) & $(81.2)$ & $(56.2)$ & $(81.2)$ & $(12.4)$ & (12.4) \\
\hline
\end{tabular}




\section{Cuadro IV \\ Resultados obtenidos en el ensayo de La ReAcción EN CADENA DE LA POLIMERASA. Ciudad de México, 2001}

\begin{tabular}{ccccccc}
$\begin{array}{c}\text { Rangos } \\
\text { de edad en } \\
\text { meses }\end{array}$ & $\begin{array}{c}\text { Verdaderos } \\
\text { positivo }\end{array}$ & $\begin{array}{c}\text { Falsos } \\
\text { positivo }\end{array}$ & $\begin{array}{c}\text { Verdaderos } \\
\text { negativo }\end{array}$ & $\begin{array}{c}\text { Falsos } \\
\text { negativo }\end{array}$ & $\begin{array}{c}\text { Sensibi- } \\
\text { lidad }\end{array}$ & $\begin{array}{c}\text { Especifi- } \\
\text { cidad }\end{array}$ \\
$0-3$ & 8 & 0 & 49 & 0 & $100 \%$ & $100 \%$ \\
\hline $4-6$ & 15 & 0 & 26 & 0 & $100 \%$ & $100 \%$ \\
\hline $7-12$ & 16 & 0 & 37 & 1 & $94.11 \%$ & $100 \%$ \\
\hline $13-18$ & 6 & 0 & 27 & 0 & $100 \%$ & $100 \%$ \\
\hline $19-24$ & 12 & 0 & 13 & 0 & $100 \%$ & $100 \%$ \\
\hline Totales & 57 & 0 & 152 & 1 & $98.27 \%$ & $100 \%$
\end{tabular}

los rangos de edad $(1 / 153)$ y permitiría utilizar la prueba de ELISA con más seguridad en cuanto a falsas reacciones positivas en lugares donde no se tenga la posibilidad de detectar anticuerpos tipo IgA por inmunoblot.

Los datos de sensibilidad y especificidad obtenidos para el inmunoblot indican que es una prueba moderadamente sensible $(89.18 \%)$ y de buena especificidad $(96.15 \%)$ en niños mayores de tres meses de edad, lo cual concuerda con observaciones hechas por otros autores. ${ }^{6-16}$ Cabe señalar que las muestras no fueron pre-tratadas para eliminar IgG materna, pues el inmunoblot utilizado no es comercial y emplea antígeno viral completo, sin embargo la sensibilidad y especificidad del ensayo es mejor que la reportada por Kline y colaboradores, ${ }_{1}^{11}$ quienes sólo detectan 10/19 niños infectados para una sensibilidad de 53\% En el ensayo de inmunoblot no se pudo detectar la presencia de anticuerpos específicos frente IgA de VIH-1 en 16 niños confirmadamente infectados, 10 de los cuales eran menores de seis meses de edad. En lo referente a los anticuerpos presentes en niños menores de cuatro meses de edad nosotros pudimos observar en 10/16 niños de esta edad anticuerpos a más de tres proteínas virales incluyendo gp160 y p24, lo cual difiere con las observaciones hechas por Weiblen y colaboradores ${ }^{17}$ en que sólo detectan anticuerpos a gp160 y/o p24 en niños menores de cuatro meses de edad.

Los datos de este estudio muestran que la PCR es muy sensible y muy específica en el diagnóstico de VIH-1 en niños menores de 24 meses de edad, sin embargo, es muy importante tener en cuenta que el no poder detectar el virus en las primeras semanas de vida no excluye la infección en el niño, ya que se ha demostrado que si la infección se adquirió en el momento del parto o después del parto el número de células infectadas puede ser muy reducido y estar por debajo de los límites de detección, tanto del cultivo viral como de la PCR. ${ }^{11,12,14-18}$

De igual modo se ha demostrado que un bebé no infectado puede haber adquirido de su madre fragmentos no replicativos de genoma viral que se detectan en la prueba de la PCR ${ }^{17}$ En nuestra experiencia también hemos encontrado niños con la PCR repetidamente positiva con varios pares de iniciadores que no han seroconvertido ni mostrado replicación viral a lo largo de varios años. Por este motivo se recomienda no utilizar la PCR como único ensayo diagnóstico, confirmar un resultado positivo con una nueva muestra, tener mucho cuidado en la interpretación de los resultados en los recién nacidos y evaluar los datos a la luz de los hallazgos clínicos. También hay reportes de cultivo viral positivo en niños muy pequeños (menores de 2 semanas de edad) no infectados ${ }^{19}$ por lo que es importante volver a intentar el aislamiento 2 ó 3 meses después, antes de dar por confirmado el diagnóstico de infección.

Con base en los datos obtenidos en este estudio, podemos concluir que es posible hacer el diagnóstico perinatal del VIH-1 utilizando la PCR y detección de anticuerpos IgA específicos para el VIH-1 por inmunoblot. Cuando estas dos pruebas se realizaron de modo simultáneo la sensibilidad fue de $100 \%$ con límites de confianza de $95 \%(91.11-100)$ y la especificidad de $97.11 \%$, con límites de confianza de 95\% (91.1899.25) en el diagnóstico inicial. Sin embargo, es importante hacer notar que ante resultados discrepantes en los ensayos deben solicitarse nuevas muestras y repetir las pruebas. No es conveniente dar un diagnóstico final de no-infección mientras no hayan desaparecido los anticuerpos maternos tipo IgG lo cual ocurre en la mayoría de los casos entre los 12 y 18 meses de vida.

\section{Referencias}

1. N ewell ML, Peckham C. Risk factors for vertical transmission of HIV-1 and early markers of HIV-1 infection in children.AIDS 1993; 7:

S591-S597.

2.Van de Perre P. Postnatal transmission of human immunodeficiency virus type 1:The breast-feeding dilemma. Am J 0 bstet Gynecol 1995; 173: 483-487.

3. Committee on Pediatric AIDS. Human milk, breastfeeding and transmission of human immunodeficiency virus in the United States. Pediatrics 1995; 96:977-979.

4. Schüpbach J, Tomasik Z, Jendis J, Böni J, Seger R, Kind Ch et al. IgG , IgM and IgA response to HIV in Infants born to HIV-1 infected mothers. J Acquir Immune Defic Syndr 1994; 7:421-427. 
5. European Collaborative Study. Mother-to-child transmision of HIV infection. Lancet 1988; ii: 1039-1042.

6. Moodley D, Bobat RA, C outsoudis A, Coovadia HM. Predicting perinatal human immunodeficiency virus infection by antibody patterns. Pediatr Infect D is J 1995; 14: 850-852.

7. D esrosiers RC.Virus purification, preparation of infectious virus stock, and virus storage. En:Aldo vini A, W alker B, Ed. Techniques in HIV research. N ueva York (N Y): Stockton Press; 1990: 121-127.

8. Livingston RA, Hutton N , Halsey N A, Kline RL, Joyner M, Q uinnTC. Human immunodeficiency virus-specific IgA in infants born to human immunodeficiency virus-seropositive women.Arch Pediatr Adolesc Med 1995; 149: 503-507.

9. Clerici M, Levin JM, Kessler HA, Harris A, Berzofsky JA Landay AL et al. HIV-specific T-helper activity in seronegative health care workers exposed to contaminated blood. JAMA 1994; 271: 42-46.

10. Riegelman RK, Hirsch RP. Cómo estudiar un estudio y probar una prueba: lectura crítica de la literatura médica. 2 a ed. W ashington, DC: O rganización Panamericana de la Salud; 1992; Publicación Científica N 0. 531: 112-122.

11. Kline MW, Lewis DE, Hollinger FB, Reuben JM, Hanson C , Kozinetz CA et al.A comparative study of human immunodeficiency virus culture, poymerase chain reaction and anti-human immunodeficiency virus immunoglobulin A antibody detection in the diagnosis during early infancy of vertically acquired human immunodeficiency virus infection. Pediatr Infect D is J 1994; 13: 90-94.

12. Q uinn TC, Kline RL, Halsey N, Hutton N, Ruff A, Butz A et al. Early diagnosis of perinatal HIV infection by detection of viral-specific IgA antibodies. JAMA 1991; 266: 3439-3442.
13. M cIntosh K, C omeau AM,W ara D, Díaz C, Landesman S, Pitt I et al. The utility of IgA antibody to human immunodeficiency virus type 1 in early diagnosis of vertical transmitted infection. Arch Pediatr Adolesc Med 1996; 150: 598-602.

14. Report of consensus workshop on early diagnosis of HIV infection in infants: Siena, Italy. J A cquir Immune D efic Syndr 1992, 5:1169-1178. 15. Henrard D, Fauvel J, Samson G, D elege M, Boucher C and Hankins J. 0 ntogeny of the humoral immune response to human immunodeficiency virus type 1 in infants. J Infect $D$ is 1993; 168:288-291. 16. Martin N L, Levy JA, Legg H, W eintrub PS, C owan MJ,W ara D. Detection of infection with human immunodeficiency virus (HIV) type 1 in infants by an anti-HIV immunoglobulin A assay using recombinant proteins. J Pediatr 1991; 118: 354-358.

17. Weiblen BJ, Lee FK, Cooper ER, Landesman S, McIntosh K, Harris JA et al. Early diagnosis of HIV infection in infants by detection of IgA HIV antibodies. Lancet 1990; 335:988-990.

18. N ewell ML, Loveday C, D unn D, Kaye S,Tedder R, Peckham C et al. Use of Polymerase chain reaction and quantitative antibody tests in children born to human immunodeficiency virus-1 infected mothers. J Med Virol 1995; 47:330-335.

19.W iznia AA, Lambert G, D obrosyzcki J, Porricolo M, Chelyapov N, Israeli $V$ et al.Virologic, immunologic and clinical evaluation of human immunodeficiency virus antibody status of symptom-free children born to infected mothers.J Pediatr 1994;125:352-355. 